\title{
Healthcare-associated infections in long-term care facilities (HALT) in Frankfurt am Main, Germany, January to March 2011
}

U Heudorf (ursel.heudorf@stadt-frankfurt.de) ${ }^{1}, K_{\text {Boehlcke }}^{1}$, M Schade

1. Public Health Authorities, Frankfurt am Main, Germany

Citation style for this article:

LHeudorf U, Boehlcke K, Schade M. Healthcare-associated infections in long-term care facilities (HALT) in Frankfurt am Main, Germany, January to March 2011. Euro Surveill. 2012;17(35): pii=20256. Available online: http://www.eurosurveillance.org/ViewArticle.aspx?Articleld=20256

Article submitted on 02 December 2011 / published on 30 August 2012

Healthcare-associated infections (HAls) are a potentially serious threat to elderly people living in longterm care facilities. Therefore, the European HALT (Healthcare-associated infections in long-term care facilities) project was launched in 2008. HAls and the use of antibiotics were studied in all 40 nursing homes (100\% response) in the city of Frankfurt am Main, Germany, from January to March 2011, using the HALT protocol. Of the 3,732 residents in the homes, $4.3 \%$ $(n=161)$ had either signs or symptoms of infections and/or were on oral antibiotics. The most common infections were urinary tract infections $(n=45 ; 1.2 \%)$, followed by infections of the respiratory tract $(n=41$; $1.1 \%)$ and skin except mycosis $(n=25 ; 0.7 \%)$. The overall prevalence of oral antibiotic use was $2.4 \%(n=90)$. The most frequently prescribed oral antibiotics were quinolones $(n=31)$, cephalosporins $(n=19)$, penicillins $(n=11)$ and co-trimoxazole $(n=11)$. The prevalence of HAls was about the same as that in a European pilot study carried out in November 2009 (5\%), but was higher than in several national surveys carried out between May and September 2010 (1.6-3.6\%).

\section{Introduction}

Healthcare-associated infections (HAIs) are among the most important threats to health in Europe, especially those caused by multidrug-resistant bacteria [1]. Hygiene and appropriate use of antibiotics is necessary for prevention of such infections, not only in hospitals but also in long-term care facilities (LTCFs) for elderly people. However, surveillance of HAls is mandatory in hospitals only, not in LTCFs. In various studies, the prevalence rates of these infections in LCTFs ranged from $2.8 \%$ to $32.7 \%$ [2-8] and incidence rates from 1.8 to 13.5 infections per 1,000 resident days [6,9-14]. Thus prevention of infection in LTCFs is necessary [15].

A European project called HALT (Healthcare-associated infections in long-term care facilities) was launched by the European Centre for Disease Prevention and Control (ECDC) in 2008 [16-18]. National HALT programmes were established and in 2009, a pilot point prevalence study on HAls and antibiotic use was performed in 117 nursing homes in 13 European countries
[16]. In summer 2010, a point prevalence survey on HAls and antibiotic use in European LTCFs was carried out, coordinated by ECDC, with 722 nursing homes across 25 European countries taking part [17].The aims of the HALT project are to measure and describe HAI, antibiotic use, antimicrobial resistance and current infection control/prevention practices in LTCFs all over Europe in order to establish baseline rates and identify priorities for improvement [16]. Participating LTCFs were asked to survey HAls and antibiotic use on one day, using standardised questionnaires. To date, data from the pilot study are available [16], as well as from national surveys in Ireland, Scotland, Germany and the Netherlands in 2010 [19-22].

From January to March 2011, the HALT project was conducted in nursing homes of the city of Frankfurt am Main (hereafter referred to as Frankfurt), Germany. As all the nursing homes participated, we report here on data from this $100 \%$ response.

\section{Methods}

From 4 January to 9 March 2011, all nursing homes in Frankfurt were visited by an external surveyor, who was a member of the local public health service. Data on the organisation of the homes as well as point prevalence of infections and antibiotic use were obtained according to the HALT protocol [16]. Two HALT questionnaires were used to obtain data about the institution and residents.

\section{Institutional questionnaire}

This questionnaire collected detailed information about the home, including bed capacity, staffing, number of single rooms, medical care, infection control and antibiotic stewardship practices. Data were obtained on the number of residents present at 8 a.m. of the day of the study (eligible residents, hereafter referred to as 'all residents') as well as the number of residents aged over 85 years, male residents, recent surgery, antibiotic therapy, residents with urinary or vascular catheters, pressure sores and other wounds. 


\section{Resident questionnaire}

This questionnaire was completed for all residents who were on antibiotic therapy and/or who had signs and/or symptoms of infections on the day of the survey giving data on resident demographics, recent hospital stay or surgery, presence of indwelling medical devices, incontinence, disorientation and impaired mobility. We also collected information on diabetes, which had been included in the questionnaire used for the German HALT project [20]. Details of antimicrobial therapy including type of antimicrobial agents, administration route, indication (therapeutic or prophylactic) and prescriber details were collected. We asked for information on HAls, according to the McGeer criteria [23], which were adapted by the HALT project, i.e. physician diagnosis of infection was included as a criterion in all categories of infection in order to avoid underestimation of the infection rate due to lack of on-site diagnostic testing [16]. The following infections were included: respiratory tract infection (common cold syndromes/pharyngitis, influenza-like-illness, pneumonia); urinary tract infection; eye, ear, nose and mouth infection; skin infection (cellulitis, soft tissue infection, wound infection), skin mycosis; herpes simplex and herpes zoster infection, scabies); gastrointestinal tract infections; systemic infections (primary bloodstream infection; unexplained febrile episode).

\section{Results}

Home characteristics, hygiene and organisation All 40 nursing homes in Frankfurt took part in this survey. The total number of beds was 4,308 . The percentage of single rooms per total bed capacity was $60.9 \%$ $(n=2,624)$, one home provided single rooms only, and one provided no single rooms at all. The eligible population, i.e. residents present in the home on the day of the survey, numbered 3,732 (determined from the total number of beds minus the non-occupied beds $(n=445)$, minus residents absent because of hospitalisation $(n=118)$ or other reasons $(n=13))$. The mean capacity of the homes was 108 beds (range: 23-208). All the homes provided round-the-clock professional nursing care: in 23 out of 31 homes only, at least one of the staff had special training in infection control; in the other nine homes, this information was not documented. In all the homes, standard operating procedures for hygiene and nursing had been established to ensure appropriate hygiene and prevention of infection. All homes also had written protocols for hand hygiene, management of indwelling catheters, management of meticillin-resistant Staphylococcus aureus (MRSA) infection, enteral catheters (i.e. percutaneous endoscopic gastrostomy tubes). However, an infection surveillance system was established in only one home.

In all homes, medical care was provided by private general practitioners, with up to 20 physicians in one home. In only one home, an additional so-called home physician was available, with daily presence in the home. According to the German medical system,
TABLE 1

Characteristics of residents in 40 nursing homes in Frankfurt am Main, Germany, HALT project, JanuaryMarch $2011(n=3,732)$

\begin{tabular}{|l|c|c|c|}
\hline Characteristic & $\begin{array}{c}\text { Total } \\
\text { number }\end{array}$ & $\%$ & Range (\%) \\
\hline Aged 85 years & 1,912 & 51.2 & $25.0-93.0$ \\
\hline Male & 1,063 & 28.5 & $4.6-47.4$ \\
\hline Had urinary catheter & 377 & 10.1 & $2.0-21.4$ \\
\hline Had vascular catheter & 10 & 0.3 & $0.0-1.8$ \\
\hline Had pressure sores & 158 & 4.2 & $0.0-8.8$ \\
\hline Had other wounds & 197 & 5.3 & $0.0-15.5$ \\
\hline Were disoriented & 2,215 & 59.4 & $32.9-96.8$ \\
\hline Had impaired mobility & 1,903 & 51.0 & $19.1-68.6$ \\
\hline Had surgery in the past 30 days & 50 & 1.3 & $0.0-4.6$ \\
\hline Were incontinent & 3,015 & 80.8 & $42.6-100.0$ \\
\hline $\begin{array}{l}\text { Had percutaneous endoscopic } \\
\text { gastrostomy tube }\end{array}$ & 246 & 6.6 & $0.0-21.7$ \\
\hline Had diabetes & 387 & 10.4 & $0.0-17.6$ \\
\hline
\end{tabular}

HALT: Healthcare-associated infections in long-term care facilities.

all these physicians treated only their own patients. Medical coordination of infection prevention, infection surveillance, medical activity and antibiotic stewardship was missing in all the homes.

Residents' characteristics, including risk factors for healthcare-associated infections In Table 1, the characteristics of residents at time of the study are shown.

Healthcare-associated infections and antibiotic use Of the 3,732 residents, 161 had an infection according to the adapted McGeer criteria. Table 2 summarises the infections reported: the most common sites of infection were urinary tract $(n=45)$, upper and lower respiratory tract $(n=41)$, skin $(n=25)$ and skin mycosis $(n=20)$, the eye $(n=14)$ and gastrointestinal tract $(n=11)$.

Point prevalence of all infections was $4.3 \%$, comprising $1.2 \%$ urinary tract infections, $1.1 \%$ respiratory tract infections, $0.7 \%$ skin infections except mycosis, $0.5 \%$ skin mycosis, $0.4 \%$ eye infections, $0.3 \%$ gastrointestinal tract infections and $0.1 \%$ mouth infection (periodontitis). We included three residents diagnosed by physicians as having HIV infection, although the HIV infections were not nosocomial, as they were treated prophylactically with oral antibiotics (Table 2). Other infections mentioned in the McGeer criteria such as bacteraemia and scabies did not occur.

Table 3 shows the odds ratios for HAls by residents' characteristics. Residents with an indwelling urinary 
TABLE 2

Prevalence of healthcare-associated infections in 3,732 residents of 40 nursing homes in Frankfurt am Main, Germany, HALT project, January-March 2011

\begin{tabular}{|c|c|c|c|}
\hline \multirow{2}{*}{ Type of infection } & Infected residents $\mathrm{n}=161$ & \multicolumn{2}{|c|}{ All residents $n=3,732$} \\
\hline & $\begin{array}{l}\text { Number of residents with } \\
\text { the infection }(\%)\end{array}$ & $\begin{array}{l}\text { Percentage of infected residents } \\
\text { per total number of residents }\end{array}$ & $\begin{array}{c}\text { Range of percentage infection } \\
\text { in the homes }\end{array}$ \\
\hline Urinary tract & $45(28.0)$ & 1.2 & $0.0-8.7$ \\
\hline Respiratory tract & $41(25.5)$ & 1.1 & $0.0-4.3$ \\
\hline Skin infection, except mycosis & $25(15 \cdot 5)$ & 0.7 & $0.0-7.8$ \\
\hline Skin mycosis & $20(12.4)$ & 0.5 & $0.0-4.3$ \\
\hline Eye & $14(8.7)$ & 0.4 & $0.0-12.5$ \\
\hline Gastrointestinal tract & $11(6.8)$ & 0.3 & $0.0-2.4$ \\
\hline Mouth (periodontitis) & $2(1.2)$ & 0.1 & $0.0-1.2$ \\
\hline Other ${ }^{\mathrm{a}}$ & $3(1.9)$ & 0.1 & $0.0-1.5$ \\
\hline Total & $161(100.0)$ & $4 \cdot 3$ & - \\
\hline
\end{tabular}

HALT: Healthcare-associated infections in long-term care facilities.

a Three residents diagnosed by physicians as having HIV infection were included although the HIV infections were not nosocomial, as the residents were treated prophylactically with oral antibiotics.

catheter, pressure sores, other wounds or diabetes had significantly higher odds for having an HAI . Having a urinary catheter, pressure sores as well as a vascular catheter or diabetes were each found to increase significantly the odds of urinary tract infection. The odds of skin infection were significantly increased by the presence of pressure sores, other wounds or diabetes. However, sex, age, incontinence and dementia (disoriented residents) were not significantly related to a higher risk of having any HAl or of having urinary tract, respiratory tract or skin infections except mycosis. Hence, sex, age, incontinence and dementia proved not to be risk factors for infection.
Of the 161 residents with an $\mathrm{HAl}, 90$ (55.9\%) were being treated with oral antibiotics, one (0.6\%) resident was treated intravenously and $27(16.8 \%)$ with topical antibiotics; for the remaining $43(26.7 \%)$, no antibiotics had been prescribed (Table 4). Oral antibiotics were prescribed mainly for urinary tract infections $(n=39)$ or respiratory tract infections $(n=28)$, less often for skin infections except mycosis $(n=15)$ and gastrointestinal tract infections $(n=4)$. Topical antibiotics were prescribed to 27 residents, to 18 residents for treatment of skin infections and skin mycosis and to 9 residents for eye infection. About $90 \%$ of the oral antibiotics were for therapeutic use, while $10 \%$ were used prophylactically.

\section{TABLE 3}

Odds ratios for healthcare-associated infections by residents' characteristics (161 residents of 40 nursing homes), Frankfurt am Main, Germany, HALT project, January-March 2011

\begin{tabular}{|c|c|c|c|c|}
\hline \multirow[b]{2}{*}{ Type of infection } & \multicolumn{4}{|c|}{ Odds ratio $(95 \% \mathrm{Cl})$} \\
\hline & $\begin{array}{l}\text { All infections } \\
n=161\end{array}$ & $\begin{array}{l}\text { Urinary tract infections } \\
\qquad n=45\end{array}$ & $\begin{array}{c}\text { Respiratory } \\
\text { tract infections } \\
n=41\end{array}$ & $\begin{array}{l}\text { Skin infections, } \\
\text { except mycosis } \\
n=25\end{array}$ \\
\hline Male & $0.823(0.572-1.186)$ & $1.259(0.675-2.350)$ & $0.514(0.227-1.163)$ & $0.976(0.407-2.344)$ \\
\hline Aged $>85$ years & $1.096(0.798-1.504)$ & $0.995(0.553-1.792)$ & $1.659(0.876-3.142)$ & $0.746(0.338-1.649)$ \\
\hline Had urinary catheter & $3.058(2.096-4.460)$ & $8.187(4.512-14.855)$ & $0.962(0.341-2.713)$ & $1.703(0.581-4.986)$ \\
\hline Had pressure sores & $2.463(1.411-4.299)$ & $2.887(1.124-7.419)$ & $0.563(0.077-4.120)$ & $5.807(2.151-15.680)$ \\
\hline Had other wounds & $2.385(1.428-3.983)$ & $0.405(0.055-2.954)$ & $0.446(0.061-3.260)$ & $12.549(5.563-28.310)$ \\
\hline Disoriented & $0.700(0.510-0.960)$ & $1.028(0.564-1.873)$ & $0.588(0.317-1.090)$ & $0.536(0.243-1.183)$ \\
\hline Incontinent & $1.040(0.694-1.560)$ & $2.457(0.877-6.883)$ & $0.734(0.358-1.505)$ & $0.951(0.356-2.542)$ \\
\hline Had surgery in the past 30 days & $2.511(0.983-6.415)$ & $3.526(0.830-14.974)$ & NA & $3.111(0.413-23.452)$ \\
\hline Had vascular catheter & $2.474(0.311-19.644)$ & $9.288(1.152-74.889)$ & NA & NA \\
\hline Had diabetes & $2.642(1.795-3.890)$ & $2.849(1.432-5.670)$ & $1.489(0.564-3.622)$ & $2.757(1.094-6.945)$ \\
\hline
\end{tabular}

HALT: Healthcare-associated infections in long-term care facilities; NA: not applicable.

Numbers in bold figures are statistically significant odds ratios. 
Antibiotics prescribed for healthcare-associated infections in 40 nursing homes in Frankfurt am Main, Germany, HALT project, January-March $2011(\mathrm{n}=161)$

\begin{tabular}{|c|c|c|c|c|}
\hline \multirow[b]{2}{*}{ Type of infection } & \multicolumn{4}{|c|}{ Infected residents } \\
\hline & Number infected & $\begin{array}{l}\text { Number given } \\
\text { oral antibiotics }\end{array}$ & $\begin{array}{l}\text { Number given } \\
\text { topical antibiotics }\end{array}$ & $\begin{array}{l}\text { Number given } \\
\text { no antibiotics }\end{array}$ \\
\hline Urinary tract & 45 & 39 & 0 & 5 \\
\hline Respiratory tract & 41 & 28 & 0 & 13 \\
\hline Skin, except mycosis & 25 & 15 & 3 & 7 \\
\hline Skin mycosis & 20 & 1 & 15 & 4 \\
\hline Eye & 14 & 0 & 9 & 5 \\
\hline Gastrointestinal tract & 11 & 4 & 0 & 7 \\
\hline Other $^{\mathrm{a}}$ & 3 & 3 & 0 & 0 \\
\hline Mouth (periodontitis) & 2 & 0 & 0 & 2 \\
\hline Total & $161^{b}$ & 90 & 27 & 43 \\
\hline
\end{tabular}

HALT: Healthcare-associated infections in long-term care facilities.

a Three residents diagnosed by physicians as having HIV infection were included although the HIV infections were not nosocomial, as the residents were treated prophylactically with oral antibiotics.

b Includes one resident treated intravenously with antibiotics.

The majority of the antibiotics were prescribed in the nursing homes $(81 \%(73 / 90)$ of the oral and all of the 27 topical antibiotic prescriptions), whereas 17 (19\%) of the oral antibiotics had been prescribed in hospital. Most antibiotics were prescribed by a general practitioner (59 (66\%) of the oral and 26 (96\%) of the topical antibiotics), 21 (23\%) of the oral and 1 (4\%) of the topical antibiotics had been prescribed by a specialist (i.e. urologist and ophthalmologist) and 10 (11\%) of the oral antibiotics by an emergency specialist.

The most frequently prescribed oral antibiotics were quinolones $(n=31)$, other beta-lactam antibacterials $(n=19), 17$ of which were second-generation cephalosporins and two of which third-generation cephalosporins, penicillins $(n=11)$ and co-trimoxazole (combination of a sulfonamide and trimethoprim) $(n=11)$. A total of 19 of the 45 residents with urinary tract infections, 6 of the 25 residents with skin infections except mycosis and 6 of the 41 residents with respiratory tract infections received quinolone therapy. Antivirals were given to two residents with skin infection (no mycosis) and to another with skin mycosis. Penicillins or cephalosporins were given to 14 of the residents with respiratory tract infections, to eight of those with urinary tract infections and to six of those with skin infections except mycosis. Seven urinary tract infections were treated with co-trimoxazole and four with nitrofurantoin (Table 5).

Oral antibiotics were given for 39 urinary tract infections; however, tests had been documented for only 17 of the 39 before therapy (in 14 cases, a urine stick test had been used and in three, microbiological tests had been carried out).

\section{Discussion}

Due to demographic changes, more and more elderly people will depend on qualified nursing in the coming years - at home or in LTCFs: in Germany, for example, the population depending on nursing is estimated to increase between 2007 and 2030 from 2.65 million to 3.37 million [24]. Structures of LTCFs differ greatly throughout Europe, including having different nursing and medical facilities for the residents.

In Frankfurt, all homes were privately run, mostly on a non-profit basis. All residents had their own private physician, so there was no common antibiotic stewardship in the facilities.

The data of our study, conducted from January to Mach 2011, can be compared with the results of the European pilot study in November 2009 [16] as well as the prevalence studies in Ireland, June 2010 [19], Germany, May to September 2010 [20], Scotland, July 2010 [21], and the Netherlands, May to June 2010 [22] (Table 6). The residents in our study were older, more often incontinent than in all other studies cited. More of them also had an indwelling urinary catheter than the residents of the Irish and Scottish cohorts, whereas prevalence of a urinary catheter was roughly the same as in the pilot study and the German and Dutch cohorts. The Frankfurt residents exhibited fewer pressure sores and other wounds compared with the pilot study and the Irish cohort, whereas the rate was nearly the same in the German study. The rate of impaired mobility was comparable to that in the pilot study and the Irish survey, was lower than in the Dutch study, but was higher than in the Scottish and German national surveys. 
Oral antibiotics prescribed for healthcare-associated infections in 40 nursing homes in Frankfurt am Main, Germany, HALT project, January-March $2011(\mathrm{n}=90)$

\begin{tabular}{|c|c|c|c|c|}
\hline \multirow[b]{2}{*}{ Type of infection } & \multicolumn{4}{|c|}{ Infected residents } \\
\hline & $\begin{array}{c}\text { All } \\
\text { infections }\end{array}$ & $\begin{array}{l}\text { Respiratory tract } \\
\text { infections }\end{array}$ & $\begin{array}{l}\text { Urinary tract } \\
\text { infections }\end{array}$ & $\begin{array}{l}\text { Skin infections, } \\
\text { except mycosis }\end{array}$ \\
\hline J01A Tetracyclines & 4 & 3 & 0 & 1 \\
\hline J01C Beta-lactam antibacterials, penicillins & 11 & 7 & 1 & 3 \\
\hline J01D Other beta-lactam antibacterials & 19 & 7 & 7 & 3 \\
\hline J01E Sulfonamides and trimethoprim & 11 & 2 & 7 & o \\
\hline Jo1F Macrolides, lincosamides and streptogramins ${ }^{a}$ & 4 & 3 & 0 & o \\
\hline J01M Quinolone antibacterials & 31 & 6 & 19 & 6 \\
\hline J01X Other antibacterials ${ }^{b}$ & 6 & 0 & 4 & 0 \\
\hline J05 Antivirals for systemic use ${ }^{c}$ & 3 & 0 & 0 & 2 \\
\hline No data & 1 & 0 & 1 & 0 \\
\hline Total & 90 & 28 & 39 & 15 \\
\hline
\end{tabular}

HALT; Healthcare-associated infections in long-term care facilities.

a Only macrolides $(n=2)$ and lincosamides $(n=2)$ were used.

b Nitrofurantoin was used.

Given to two residents with skin infection (no mycosis) and to a third with skin mycosis.

The infection prevalence was $4.3 \%$ and thus roughly the same as the prevalence in the pilot study, but higher than in the national studies published. This might be influenced by the season: our study, like the pilot study, had been carried out in autumn/winter (between November and March), whereas the other cited national surveys were carried out between May and September. In all studies, infections of the respiratory tract, urinary tract and skin infection were the most abundant. The $1.2 \%$ prevalence of urinary tract infections in our study is less than that in the Irish and the Scottish studies although indwelling urinary catheters were used much more often in the Frankfurt homes than in Irish and Scottish LTCFs. However, the prevalence of urinary tract infections in our study was higher than in the German and Dutch studies.

The prevalence of all HAls was less than in the pilot study, but higher than in the other four studies. Comparability of the data may be limited, as in three other studies (in Ireland, Germany and Scotland), the data were collected by staff from each nursing home, whereas in our study and that from the Netherlands, all homes were visited by the same external surveyor, documenting the data in the same standardised way. Moreover, in our study, all homes agreed to participate in the study (100\% response rate), so any bias related to the voluntary participation of homes that are especially interested in the subject need not to be taken into account.

Although the Frankfurt study was done to from January to March, the prevalence of respiratory infections was low, compared with the pilot study (November 2009), but higher than the German, Irish and Scottish ones, which were carried out between June and September 2010 , and no influenza was reported. However, $3 \%$ of the residents were in hospital on the day of investigation and some of them might have been hospitalised because of infections, pneumonia, etc.

Although antibiotics were prescribed by external private physicians in the Frankfurt LTCFs and there were no standard guidelines for antibiotic therapy in the homes, the use of oral antibiotics was low (2.4\%) in our study compared with the pilot study (5.2\%), the Irish study (10.2\%), the Dutch study (3.5\%) and the Scottish study $(7.3 \%)$. It was roughly comparable to the German study (1.15\%), though somewhat higher. Antibiotic prescription for prophylactic reasons was $10 \%$ and thus in line with the German national survey (6.4\%), but much lower than in Ireland and Scotland, where $42 \%$ and $48 \%$ of the cases received antibiotics for prophylaxis. The German guidelines of the Paul Ehrlich Society for antibiotic therapy [25] of ambulatory infections seem to have been followed in the Frankfurt nursing homes, although compliance to these guidelines is not obligatory. In these guidelines, regarding infections of the lower respiratory tract in persons at risk (i.e. residents of LTCFs), the first choice for therapy is beta-lactam antibacterials, with quinolones and third-generation cephalosporins as second choice. With regard to urinary tract infections, acute cystitis should be treated with trimethoprim and sulfonamides, with third-generation cephalosporins as a second alternative. The firstchoice antibiotic for pyelonephritis are quinolones, alternatives are trimethoprim and sulfonamides, with third-generation cephalosporins and penicillins with an extended beta-lactamase spectrum [25-27]. 
Characteristics of residents and healthcare-associated infections in the Frankfurt HALT study 2011, compared with previous HALT projects

\begin{tabular}{|c|c|c|c|c|c|c|}
\hline \multirow{3}{*}{ Characteristic } & Frankfurt, Germany & $\begin{array}{c}\text { European } \\
\text { pilot study } \\
(13 \text { countries })\end{array}$ & Ireland & Germany & Scotland & $\begin{array}{l}\text { The } \\
\text { Netherlands }\end{array}$ \\
\hline & Jan-March 2011 & Nov 2009 & Jun 2010 & May-Sep 2010 & Jul 2010 & May-Jun 2010 \\
\hline & $\%\left(\right.$ range) ${ }^{a}$ & $\%^{a}$ & $\%^{a}$ & $\%^{a}$ & $\%^{a}$ & $\%^{\mathrm{a}}$ \\
\hline Number of homes & 40 & 117 & 69 & 73 & 83 & 10 \\
\hline Number of residents & 3,732 & 14,491 & 4,170 & 6,496 & 4,870 & 1,429 \\
\hline \multicolumn{7}{|l|}{ Residents } \\
\hline Aged $>85$ years & $51.2(25.0-93.0)$ & 44.3 & $34 \cdot 3$ & 47.6 & 40.8 & 40 \\
\hline Male & $28.5(4.6-47.4)$ & 25.8 & NR & 26.6 & $25 \cdot 7$ & 32 \\
\hline Incontinent & $80.8(42.6-100.0)$ & 67.5 & 63.0 & 74.5 & 61.3 & 61 \\
\hline Disoriented & $59.4(32.9-96.8)$ & 55.1 & 50.6 & 56.7 & 57.6 & 59 \\
\hline Had Impaired mobility & $51.0(19.1-68.6)$ & 51.1 & 52.4 & 44.8 & 34.8 & 57 \\
\hline Had urinary catheter & $10.1(2.0-21.4)$ & 9.1 & 5.6 & 10.2 & 7.4 & 12 \\
\hline Had vascular catheter & $0.3(0.0-1.8)$ & 1.5 & 0.3 & 0.2 & 0.0 & 0 \\
\hline Had pressure sores & $4.2(0.0-8.8)$ & 6.7 & 2.9 & 3.8 & 2.9 & 7 \\
\hline Had other wounds & $5.3(0.0-15.5)$ & 8.0 & 9.4 & 5.1 & 4.1 & NR \\
\hline Had surgery in the past 30 days & $1.3(0.0-4.6)$ & 2.0 & 1.1 & 1.8 & 0.0 & 3 \\
\hline \multicolumn{7}{|l|}{ Infection type } \\
\hline Urinary tract infection & $1.2(0.0-8.7)$ & 1.50 & 1.5 & 0.6 & 1.4 & 0.7 \\
\hline Respiratory tract infection & $1.1(0.0-4.3)$ & 2.10 & 1 & 0.3 & 0.5 & NR \\
\hline Skin infection except mycosis & $0.7(0.0-7.8)$ & 0.68 & \multirow{2}{*}{0.7} & 0.4 & 0.4 & NR \\
\hline Skin mycosis & $0.5(0.0-4.3)$ & NR & & NR & 0.0 & NR \\
\hline Eye & $0.4(0.0-12.5)$ & 0.19 & 0.1 & \multirow{2}{*}{0.03} & 0.2 & NR \\
\hline Mouth & $0.1(0.0-1.2)$ & 0.03 & 0.1 & & 0.1 & NR \\
\hline Gastrointestinal tract & $0.3(0.0-2.4)$ & 0.23 & 0.2 & 0.09 & 0.0 & NR \\
\hline Other & $0.1^{\mathrm{b}}(0.0-1.5)$ & 0.08 & NR & NR & 0.0 & NR \\
\hline Prevalence of all infections & 4.3 & 4.98 & 3.6 & 1.6 & 2.6 & 2.8 \\
\hline \multicolumn{7}{|l|}{ Antibiotic therapy } \\
\hline $\begin{array}{l}\text { Number of residents undergoing } \\
\text { oral antibiotic therapy }\end{array}$ & 90 & 762 & 426 & 75 & 357 & 50 \\
\hline Prevalence of oral antibiotic therapy & 2.4 & 5.4 & 10.2 & 1.15 & 7.3 & 3.5 \\
\hline
\end{tabular}

HALT; Healthcare-associated infections in long-term care facilities; NR: data not reported.

a Unless otherwise indicated.

b Three residents diagnosed by physicians as having HIV infection were included although the HIV infections were not nosocomial, as the residents were treated prophylactically with oral antibiotics.

Source: European pilot study [16] and studies from Ireland [19], Germany [20], Scotland [21] and the Netherlands [22].

In only six (3\%) of the 161 infections identified in our study were the results of microbiological tests available, i.e. in 155 infections neither the bacteria nor antibiogram was available. This level is in line with data from the German survey, but far lower than in the Scottish survey.

All the Frankfurt homes have been supplied with the aggregated data as well as those relating to their particular home. The data have been discussed with the homes and the physicians in order to achieve further improvements in antibiotic therapy and restrictions for the use of invasive medical devices, which are wellknown risk factors for HAls [28,29].
Our data can serve as baseline data for forthcoming surveillance studies in Frankfurt, thus giving an opportunity for observation of trends in the Frankfurt nursing homes. Furthermore, the Frankfurt data and national German data could be used as reference for future HALT projects in Germany, which would preferably be coordinated by the local or regional public health services in addition to the hygiene control visits they are obliged to conduct according to the German Protection against Infection Act.

Because of the standardised and harmonised methodology, it is possible to compare the data from various HALT surveys in other European countries. Such 
comparisons, including a discussion of differences seen, i.e. in antibiotic stewardship, can help to prevent infections and the further increase in the prevalence of multidrug-resistant organisms.

\section{References}

1. European Commission. Public consultation on strategies for improving patient safety by prevention and control of healthcare-associated infections. Luxembourg: European Commission. [Accessed 26 Aug 2012]. Available from:http:// ec.europa.eu/health/ph threats/com/conso1 txt en.pdf

2. Engelhart S, Lauer A, Simon A, Exner D, Heudorf U, Exner $M$. [Repeated prevalence investigations of nursing homeassociated infections as a tool to assess the hygienic quality of care]. Bundesgesund $\neg$ heitsblatt Gesundheitsforsch Gesundheitsschutz. 2009;52(10):936-44. German.

3. Andersen BM, Rasch M. Hospital-acquired infections in Norwegian long-term-care institutions. A three-year survey of hospital-acquired infections and antibiotic treatment in nursing/residential homes, including 4500 residents in Oslo. Hosp Infect. 2000;46(4):288-96.

4. Eriksen HM, Iversen BG, Aavitsland P. Prevalence of nosocomial infections and use of antibiotics in long-term care facilities in Norway, 2002 and 2003. J Hosp Infect. 2004;57(4):316-20.

5. Nicolle LE, Garibaldi RA. Infection control in long-term-care facilities. Infect Control Hosp Epidemiol. 1995 16(6):348-53.

6. Stone SP. Soil, seed and climate: developing a strategy for prevention and management of infections in UK nursing homes. J Hosp Infect. 1999;43 Suppl:S29-38.

7. Nicolle LE, Strausbaugh LJ, Garibaldi RA. Infections and antibiotic resistance in nursing homes. Clin Microbiol Rev. 1996;9(1):1-17.

8. Moro ML, Mongardi M, Marchi M, Taroni F. Prevalence of longterm care acquired infections in nursing and residential homes in the Emilia-Romagna Region. Infection. 2007;35(4):250-5.

9. Stevenson KB, Moore J, Colwell H, Sleeper B. Standardized infection surveillance in long-term care: interfacility comparisons from a regional cohort of facilities. Infect Control Hosp Epidemiol. 2005;26(3):231-8.

10. Mylotte JM. Analysis of infection control surveillance data in a long-term facility: use of threshold testing. Infect Control Hosp Epidemiol. 1996;17(2):101-7.

11. Heudorf U, Schulte D. [Surveillance of nosocomial infections in a long-term care facility. Incidence and risk factors]. Bundesgesundheitsblatt Gesundheitsforsch Gesundheitsschutz. 2009;52(7):732-744. German.

12. Engelhart ST, Hanses-Derendorf L, Exner M, Kramer MH. Prospective surveillance for health care-associated infections in German nursing home residents. J Hosp Infection. 2005;60(1):46-50.

13. Jackson MM, Fierer J, Barrett-Connor E, Fraser D, Klauber $M R$, Hatch R, et al: Intensive surveillance for infections in a three-year study of nursing home patients. Am J Epidemiol.. 1992;135(6):685-96.

14. Makris AT, Morgan L, Gaber DJ, Richter A, Rubino JR. Effect of a comprehensive infection control program on the incidence of infections in long-term care facilities. Am J Infect Control. 2000;28(1):3-7.
15. Smith PW, Rusnak PG. Infection prevention and control in the long-term care facility. SHEA Long-Term-Care Committee and APIC Guidelines Committee. Infect Control Hosp Epidemiol. 1997;18(12):831-49.

16. Latour K, Jans B, the HALT management team. Healthcare associated infections in long-term care facilities. Results of the pilot point prevalence survey. November 2009. Deposit number D/2011/2505/8; IPH/Epi-report number: 2011-006. [Accessed 26 Aug 2012]. Available from: http://halt.wiv-isp.be/report/ Reports/HALT-1/HALT\%20Report\%20Pilot\%20Survey\%20 Nov\%202009.pdf

17. European Centre for Disease Prevention and Control (ECDC). About HALT-2. Background. Stockholm: ECDC. [Accessed 26 Aug 2012]. Available from: http://halt.wiv-isp.be/about/page/ background.aspx

18. European Centre for Disease Prevention and Control (ECDC). The HALT project. How to perform a successful HALT Point Prevalence Survey (PPS)? 2009-2010.. Stockholm: ECDC. HALT_PPS2. [Accessed 26 Aug 2012]. Available from: http:// halt.wiv-isp.be/manual/Study\%2odocuments\%20PPS2/Forms/ Alltems.aspx

19. Health Protection Surveillance Centre (HPSC). European point prevalence survey on healthcare associated infections and antibiotic use in long-term care facilities. National report Republic of Ireland. November 2010. Dublin: HPSC. [Accessed 26 Aug 2012]. Available from: http://www.hpsc.ie/hpsc/AZ/ MicrobiologyAntimicrobialResistance/InfectionControland HAl/ Surveillance/HCAlinlongtermcarefacilities/HALTproject2010/ Results/File,4723,en.pdf

20. Wischnewski N, Mielke M, Wendt C. [Healthcare-associated infections in long-term care facilities (HALT). German results of the European prevalence study HALT]. Bundesgesundheitsblatt Gesundheitsforsch Gesundheitsschutz. 2011;54(11):1147-52. German.

21. Health Protection Scotland (HPS). Healthcare associated infections in European long term care facilities (HALT). Prevalence study 2010 in Scotland. Glasgow: HPS; June 2011. [Accessed 26 Aug 2012] Available from: http://www. documents.hps.scot.nhs.uk/hai/sshaip/publications/halt/haltprevalence-2010.pdf

22. Eilers R, Veldman-Ariesen MJ, Haenen A, van Benthem BH. Prevalence and determinants associated with healthcareassociated infections in long-term care facilities (HALT) in the Netherlands, May to June 2010. Euro Surveill. 2012;17(34): pii=20252. Available from: http://www. eurosurveillance.org/ViewArticle.aspx?Articleld =20252

23. McGeer A, Campbell B, Emori TG, Hierholzer WJ, Jackson MM, Nicolle LE, et al. Definitions of infection for surveillance in long-term care facilities Am J Infect Control. 1991;19(1):1-7.

24. Statistische Ämter des Bundes und der Länder, editor. Demografischer Wandel in Deutschland. Auswirkungen auf Krankenhausbehandlungen und Pflegebedürftige im Bund und in den Ländern. [Demographic change in Germany. Impact on hospital therapies and requirements for nursing in the Federal Republic of Germany and the German Federal States]. Wiesbaden: Statistisches Bundesamt; 2010. German. Available from: http://www.statistikportal.de/statistik-portal/ demografischer_wandel_heft2.pdf

25. Lode H, Stahlmann R, Skopnik H. Rationaler Einsatz oraler Antibiotika bei Erwachsenen und Schulkindern (Lebensalter ab 6 Jahre). Empfehlungen einer Expertenkommission der Paul-Ehrlich-Gesellschaft für Chemotherapie e. V. [Rational use of oral antibiotics in adults and school children (children above 6 years). Findings of an expert commission of the Paul Ehrlich Society for Chemotherapy]. Chemotherapie Journal. 2006;15:129-44. [Accessed 26 Aug 2012]. German. Available from: http://www.chemotherapie-journal.de/archiv/ artikel/2006/05/148.html

26. Arbeitsgemeinschaft der Wissenschaftlichen Medizinischen Fachgesellschaften (AWMF). Harnwegsinfektionen bei erwachsenen Patienten, unkomplizierte bakterielle ambulant erworbene: Epidemiologie, Diagnostik, Therapie und Management. [Urinary infections. Epidemiology, diagnosis, therapy and management of community acquired urinary infections in adults]. Register number 043-044.Classification. Düsseldorf: AWMF. [Accessed 26 Aug 2012]. German. Available from: http://www.awmf.org/leitlinien/detail/ll/o43-044.html,

27. Höffken G, Lorenz J, Kern W, Welte T, Bauer T, Dalhoff K, et al. [Guidelines for the epidemiology, diagnosis, antimicrobial therapy and management of community-acquired pneumonia and lower respiratory tract infections in adults]. Dtsch Med Wochenschr. 2010;135(8):359-65. German.

28. Crnich CJ, Drinka P. Medical device-associated infections in the long-term care setting. Infect Dis Clin N Am. 2012;26(1):143-64.

29. von Eiff C, Jansen B, Kohnen W, Becker K. Infections associated with medical devices: pathogenesis, management and prophylaxis. Drugs. 2005;65(2)179-214. 